\title{
The European VCD System: Facilitating Public Procurement through Criteria-to-Evidence Mapping
}

\author{
Ansgar Mondorf and Maria A. Wimmer \\ University of Koblenz-Landau, Institute for IS Research, Research Group E-Government, \\ Universitätsstraße 1, 56070 Koblenz, Germany \\ mondorf@uni-koblenz.de, wimmer@uni-koblenz.de
}

\begin{abstract}
To facilitate European Union (EU)-wide interoperability in public eProcurement, the European Commission co-funds the PEPPOL project. PEPPOL aims at setting up pan-European pilot solutions that conjointly exist with national infrastructures. One of the key building blocks is the Virtual Company Dossier (VCD), an electronic cross-border document container that carries attestations and candidate statements required to evidence the fulfilment of nonexclusion and selection criteria in public tendering procedures. The attestations and candidate statements available in the various Member States often differ in their quality, relevance to certain criteria and format. In this contribution we present a concept to facilitate the correct mapping of national evidences to selection and exclusion criteria of a contracting authority from a different EU Member State. We present a solution that supports mutual recognition of diplomas, certificates or other evidence with a decision-support system called the European VCD System.
\end{abstract}

Keywords: Public Online Procurement, PEPPOL, Virtual Company Dossier, Interoperability.

\section{Introduction}

Since 2003, interoperability in eGovernment has been largely investigated in research (see e.g. [1, 2, 7, 10, 14]). Interoperability refers to the capability of information and communication technologies (ICT) systems (and their underlying business processes) to exchange information or services directly to operate effectively in collaboration contexts (cf. [8, 9]). The European Commission (EC) has established an institution that takes care of interoperability in the public sector. The Interoperable Delivery of European eGovernment Services to public Administrations, Business and Citizens (IDABC) has developed the European Interoperability Framework of which a second version is currently under revision $[8,9]$.

Existing research and practice (see e.g. [1, 2, 7, 8, 9, 10, 11, 12, 14]) distinguishes among different levels of interoperability. The following interoperability levels are put forward in the European Interoperability Framework [9]:

- Political context describes that cooperating partners need to have compatible visions, and need to focus on the same things. 
- Legal interoperability refers to the synchronisation of the legislation in the cooperating Member State so that electronic data originating in any given Member State is accorded to proper legal weight and recognition wherever it needs to be used in other Member State.

- Organisational interoperability refers to enabling processes to cooperate.

- Semantic interoperability refers to the exchange of information in an understandable way within and across organisational borders.

- Technical interoperability refers to the ability to connect systems by defining standard protocols and data formats.

A major objective of the EC is to enable European-wide eProcurement across borders by creating common principles and technical solutions that are applied within all Member States (cf. the eGovernment Action Plan [4]). According to a study by the EC, governments are the largest buyers in the European Union that purchase goods and services at a level of 1.5 billion euros (which corresponds to around $6 \%$ of the gross domestic product). However, governments are lagging behind major industries in exchanging relevant information with key actors such as economic operators. Therefore, the definition of common models for electronic data exchange is perceived as extremely relevant for companies to participate in public eProcurement. The study also reveals that by using eProcurement governments could save up to $5 \%$ on expenditure and the transaction costs for both buyers and suppliers could be reduced by $50-80 \%$ [5].

As a response to these challenges, the EC co-funds the Pan-European Public Procurement On-Line (PEPPOL) project $^{1}$ within the Competitiveness and Innovation Framework Programme (CIP) ${ }^{2}$. PEPPOL aims to set up pan-European pilot solutions for public procurement and contributes thereby to interoperable solutions for public procurement across Member State countries as well as simplifies eProcurement procedures.

One of the key building blocks of PEPPOL is the Virtual Company Dossier (VCD), an electronic cross-border document container that carries the attestations and candidate statements required in public tendering procedures. The contribution at hand will first introduce the process of a tendering procedure and the role that the European VCD System will play in it. In section 3, we present the overall concept of the European VCD System. We conclude with some lessons learned from current specification activities as well as an outlook on the next steps need for the implementation of the European VCD System.

\section{Tendering Processes and the Role of a European VCD System}

A tendering process is typically initiated by a contracting authority which prepares a call for tender based on a set of documents, usually consisting of a) the publication of a contract notice, b) the tender contract documentation, c) the technical specifications, and d) additional documents. The contract notice is produced and transmitted to an appropriate notification system such as the official gazette of the European Union, Tenders Electronic Daily (TED) ${ }^{3}-$ see step (1) in Fig. 1.

\footnotetext{
${ }^{1}$ http://www.peppol.eu/

${ }^{2}$ http://ec.europa.eu/cip/

${ }^{3} \mathrm{http}: / /$ ted.europa.eu/
} 


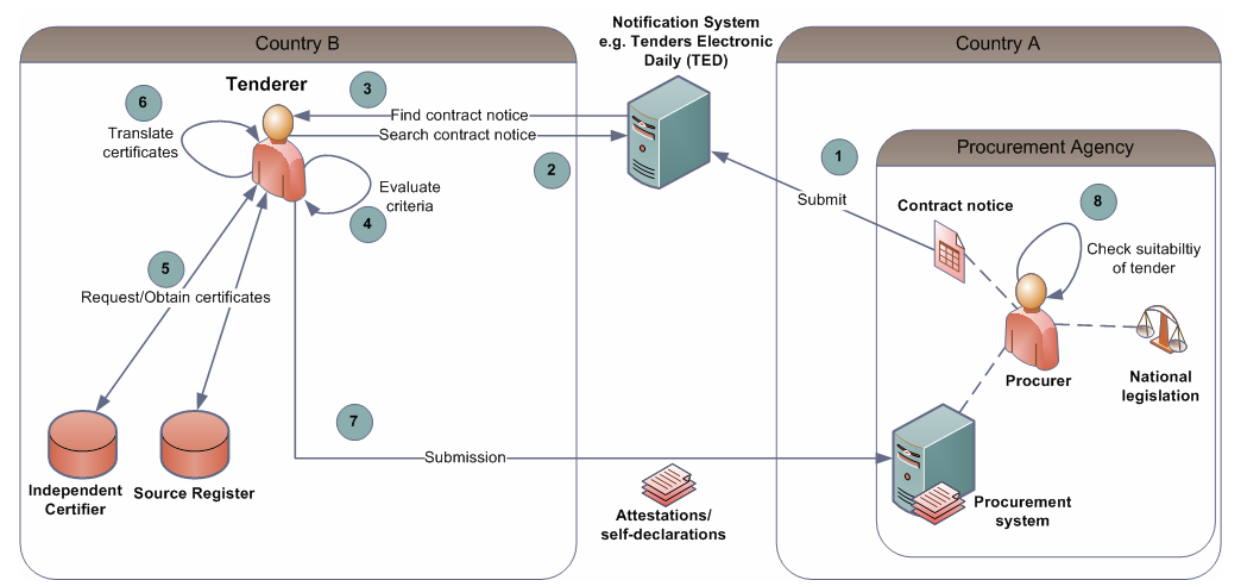

Fig. 1. Status quo procedure for participating in cross-border public procurement

An economic operator can use means such as the TED system to retrieve the relevant information about active tenders - see steps (2) or (3) in Fig. 1. TED publications of contract notices usually contain the tender and contract documentation including detailed criteria, specifications and conditions. Sometimes, the information in a contract notice provided in TED is not complete. Hence, the economic operator has to get in contact with the contracting authority in order to obtain the exact conditions pertaining to the tender and to avoid any potential failure in interpreting the requirements for participation.

If an economic operator decides to participate in a public cross-border tender, selection and exclusion criteria have to be evaluated - see step (4) in Fig. 1. This means that the economic operator has to interpret the criteria set out in the contract notice of another country and find appropriate evidence (attestations, statements, and certificates) within his/her own country to indicate compliance. These forms of evidence can either be retrieved from competent issuing bodies (e.g. certifiers, source registers, banks, public authorities) - see step (5) in Fig. 1 - or they can be issued by the economic operator himself/herself for example to indicate technical qualifications and competencies. Especially in cross-border public procurement, contracting authorities may also require the translation of specific evidence - see step (6) in Fig. 1.

Having collected all the relevant evidence and attestations, the economic operator can finally submit the dossier with all evidences to the contracting authority (together with the bid). Such documents may be distinguished by such criteria as:

a) who issues an evidence (e.g. trusted issuing bodies),

b) what quality of trust does the evidence have (e.g. self declaration, solemn statement or original evidence),

c) what replacements may exist for a given piece of evidence (self declaration, declaration on oath or solemn statement),

d) for which legal form is the evidence to be issued.

Fig. 2 visualises the taxonomy of evidences developed throughout the PEPPOL project. 


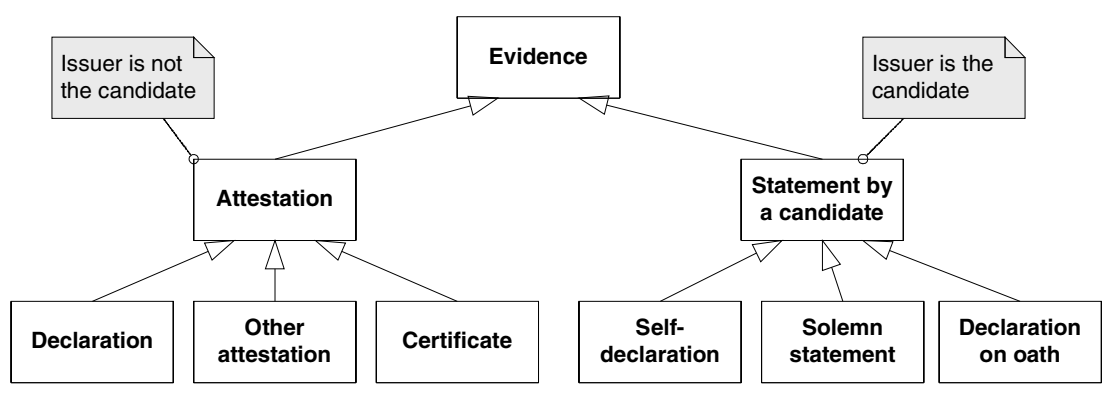

Fig. 2. Taxonomy of evidences

Another complication relates to the constellation of an economic operator. If the economic operator has one or more sub contractor(s), different evidences may be needed for the different types of tenderers. Likewise, the economic operator may be a bidding consortium with a lead tenderer and one or more further members. Each of these tenderers may also have subcontractors. The taxonomy for tenderer structures is shown in Fig. 3. In this case, the collection of evidences is affected by yet another complexity driver.

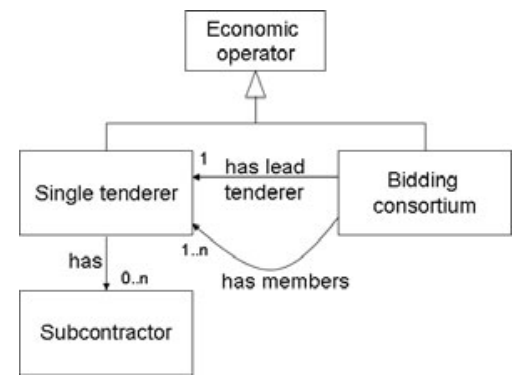

Fig. 3. Concept for the tenderer structure of economic operators

Finally, single tenderers and subcontractors may have a broad range of legal forms. Evidences do exist for specific legal forms. In some cases, evidences are to be issued only for natural persons, i.e. for persons with specific roles in the legal and organisational setup of an organisation.

As can be recognised, the step of selecting, collecting, and evaluating appropriate evidences to prove suitability becomes a major task and burden for economic operators and contracting authorities. Two different contexts drive the mode of action of both stakeholders:

- The decision about whether certificates, documents and other evidences are in conformity with the criteria of the tender is taken by the contracting authority. Contracting authorities are bodies governed by public law. They are also bound by their national provisions of public law and therefore apply their national law (lex fori). The European procurement directives are 
implemented into the various national Member States' laws; part of this law is the principle of the mutual recognition of diplomas, certificates and other evidence of formal qualification [3, 6].

- Economic operators are private entities. They operate under the national conditions of their home country and are not governed by public law. They can only provide evidence which is available in their home country and may produce candidate statements according to the foreign law of a contracting authority.

The interplay of the two different modes of action leads to difficulties, when there is a need to prove or evaluate suitability. The following two examples indicate some of the difficulties identified in the context of the PEPPOL project's VCD analysis:

- A contracting authority in Austria issues a Call for Tender and a German economic operator wishes to participate in this tendering procedure. According to Austrian law, criminal records have to be provided for all representatives of the economic operator. In Germany it is sufficient to present the criminal record of one representative. The key questions for both stakeholders are: What legislation is now applicable? How many criminal records have to be provided?

- A contracting authority in Italy requests an anti-mafia declaration. In Italy anti-mafia declarations are typically issued by competent public authorities. In most other countries, no equivalent document exists. Again, the key questions are: What legislation is now applicable? How can economic operators from other countries provide evidence that relates to this specific criterion? How will the contracting authority measure that a foreign economic operator has proved this criterion sufficiently?

These two examples demonstrate the difficulties that may occur and hinder the actors involved to operate the processes of evidence provision and evidence evaluation effectively.

The context described in this section is the starting point for conceptualising a European VCD System. The next section introduces parts of the legal and technical specifications of a European VCD System, which will provide effective and legally compliant decision-support for economic operators and contracting authorities in European cross-border public procurement.

\section{Specification of the European VCD System}

\subsection{Semantic Interoperability Model}

The European VCD System is focusing on the legal interoperability of evidences on the basis of European and national legislation. It is therefore necessary to gather national contexts and to define a basic European semantic interoperability model that supports the mutual recognition of certificates and qualification documents.

The national procurement domains are linked to a single European common domain. For every national domain a representation of the national context is developed 
which provides an overview of national criteria demanded in public procurement, and how these are evidenced. The national contexts are connected with a single European semantic interoperability model which acts as a pivotal element. Thereby, the selection and non-exclusion criteria defined within Articles 45-51 of the European Directive 2004/18/EC represent the common reference criteria, while the national criteria for individual public tenders in respective countries are considered to be the local criteria $[3,6]$.

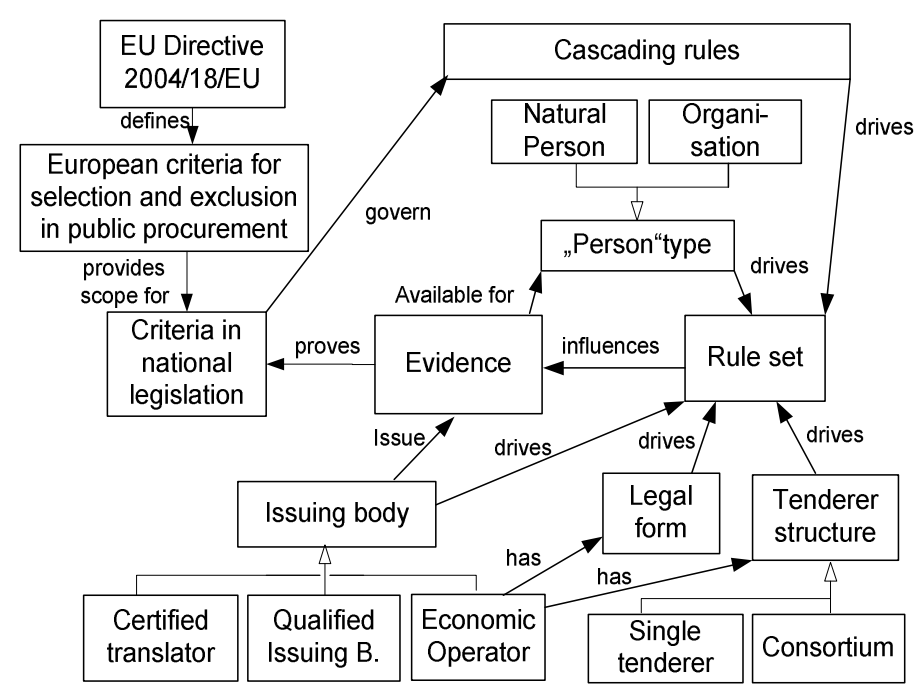

Fig. 4. Semantic interoperability model of the European VCD System

The semantic interoperability model supports basic guidance in applying the relevant community rules on mutual recognition of evidences in cross-border procurement procedures. The semantic model especially requires and provides:

- A mapping between available national evidences of economic operators and the selection and exclusion criteria set by the contracting authority in another country through European criteria. These European criteria of selection and exclusion are directly derived from Articles 45-51 of Directive 2004/18/EC [3, 6];

- A provision of a rule set supporting alternative means for evidencing criteria, when foreign economic operators are considered.

As the criteria according to the EU Directive are the same for all Member States, these criteria act as the pivotal element for the cross-border mapping in the European VCD concept. The semantic model is thereby able to clarify the relationship between national attestations of similar type and the kind of criteria to which those documents refer. In consequence, an economic operator participating in a tender published by a foreign country can quite easily understand the requirements (what criteria have to be 
fulfilled) and decide which are the best national attestations (self declarations included) to prove the criteria requested by the contracting authority when applying a specific rule set. Likewise, the contracting authority can check through the same mapping mechanism to ascertain whether the attestations submitted express fulfilment with the relevant criteria or requirements. The following subsections detail the legal rule-set and the technical specification for the European VCD System.

\subsection{Legal Specification}

As shown in Fig. 4, the legal specification of the European VCD System is driven by cascading rules, the tenderer structure, the legal form of economic operators, and the availability of evidences for specific types of persons (either legal persons or natural persons). With regard to trustworthiness and mutual recognition, the quality of the issuing body (trusted issuing body, economic operator, or statement before a notary) also plays an important role.

The cascading rules play a key role and provide a general approach for finding equivalent evidences if no comparable evidence exists in another country. It is assumed that rules with regard to mutual recognition do exist within the different countries - cross-border public procurement as such happens, even though in most Member State countries to a marginal extent. Many countries therefore have implemented with cascading rules which rank different evidence categories according to their quality and format.

In the VCD context, a cascade is understood as a series of alternative evidences that occur in successive stages or descending order, each of which is dependent on the preceding one. The cascade indicates in a ranking order which evidences should, and which alternatives could, provide a legally accepted proof of a certain criterion when no comparable evidence exists in another country. Within a national tendering procedure the contracting authority will apply its national law and, in particular, will apply the cascading rules to find out which evidence type to accept. The rules of the contracting authority will be used to justify whether the evidence will be accepted or not. If the economic operator provides evidences in the highest evidence category that is available in his/her home country (according to the descending order of the cascading rules) these evidences have to be accepted as substitute evidences by the tenderer.

In order to differentiate evidences on the European level, a concept for classifying evidences along four levels is defined (in a descending order of quality and trust) as a framework for cascading rules:

1. Evidences created by competent issuing body: Such documents are issued by an authority or trusted third party (public and private) that has the competence to provide statements in this particular domain.

2. Declaration on oath: A declaration on oath has to be declared in the presence of a competent authority. A false declaration made on oath is itself a criminal offence.

3. Solemn statement: Solemn statements are declarations where a competent body (e.g. a notary) confirms as a witness the identity of the person who is making the self declaration. This raises credibility but does not have other legal implications than the self declaration itself. Through the 
witness, trust in the person making the self declaration is intended to be increased.

4. Self-declaration: A self-declaration is an informal statement which has in principle no further legal consequence apart from offences like fraud.

The categorisation for the cascading rules is used within the different national contexts so as to define the standard evidence and the possible substitute documents or evidences that an economic operator may provide as valid proof of a particular criterion. Categories 2-4 are created by the economic operator and act as general substitute categories while category 1 is always considered to be a valid standard proof (it can be for example a tax certificate, an evidence of professional risk indemnity insurance, or a quality assurance certificate). Issuing bodies for category 1 documents receive the highest level of trust on the side of the contracting authority. They also form the highest quality of evidence.

The descending order introduced by the different categories is the basis for finding the best possible match to complement the non-existence of an evidence in a country. The economic operator's final decision with regard to substitute evidence is driven by the cascading rules ${ }^{4}$ in the country of the contracting authority. The available options in the country of the economic operator are either evidence created by a competent issuing body (category 1) or by a candidate statement produced by the economic operator (categories 2-4).

The cascading rules determine the options. If a cascading rule outlines levels 1-3 as an accepted proof of evidence then this has to be checked against the options which the economic operator has. If (1) is an available option in the country of the economic operator it has to be taken. If (1) is not available, the economic operator has to provide a candidate statement. In this case the candidate statement should be either a declaration on oath or a solemn statement (in cases where a declaration on oath cannot be produced).

This approach also applies for cases where no match to European criteria exists. For example in the case of an anti-mafia declaration, Italy has to define a virtual criterion for its national "anti-mafia" criterion and the correlating cascading rules for it. A virtual criterion is needed because the Directive does not explicitly mention this specific Italian criterion. In this case, most of the European countries do not have a matching national criterion; thus, they have to state that this criterion and rule is not applicable. Hence, the economic operator can only produce a candidate statement. The Italian cascade then defines which categories of candidate statements will be accepted.

Besides the cascading rules, the implementation of the European VCD System is influenced by other factors that are shown in Fig. 4. These rules are only briefly outlined below:

- Natural Person: Some evidences can only be issued for natural persons but they are not available for organisations. Many countries only issue criminal records for natural persons. Countries may apply different rules that

\footnotetext{
${ }^{4}$ Note: Unfortunately, cascading rules differ across EC Member States.
} 
describe which of the natural persons within an economic operator have to prove a given criterion.

- Tenderer structure: Within a tendering procedure, tenderers may participate in different roles. The major roles defined within the European VCD System are single tenderers, subcontractors and bidding consortia (with a lead contractor and further members of a consortium). Some evidences have only to be presented for a particular role (e.g. the lead contractor or the members of the consortium, but not the subcontractors).

- Legal Form: Depending on the legal basis of an economic operator, different evidences may exist to prove a given criterion. For example, evidences to prove the official enrolment in a professional register or in a trade register may depend on the legal basis of the operator.

- Field of profession: There are some evidences that depend on the field of profession. Some evidences can for example only be provided if an economic operator is member of a particular organisation which is dependent on the specific profession.

The legal rules drive the technical concept of the European VCD service. Its technical specification is outlined in the following subsection.

\subsection{Technical Specification of the European VCD Service}

In terms of technical specification of the European VCD service, Fig. 5 provides an overview of the main components and their interrelations.

The Tenders Electronic Daily (TED) interface denotes an interface to the electronic publication office of the European Union. Contract notices stored on this system could be evaluated by the European VCD System by automatic processing of the criteria defined in a particular Call for Tender.

The European VCD System must provide a functionality to calculate the evidences in the economic operator's country on the basis of national criteria published in the country of the contracting authority. For the electronic representation of the criteria and evidences, the concept of an ontology is used (for details on the ontology concept see e.g. [13]). The VCD ontology serves as data and rule set storage. It consists of different parts: the top-level ontology defines the general concepts that are applicable in all Member States and thereby set a common European (legal) framework. National ontologies are defined for each Member State in order to describe the national legislation and the mappings of national criteria to evidences. Hence, the ontology can be considered as VCD mapping tree that interconnects the legislation and evidences within the different countries through common pivotal elements, the European criteria.

The functionality for the management of the ontology and the data contained in it is provided by the component called the VCD ontology manager. The ontology manager thereby defines different rules for accessing and maintaining the various parts of the ontology. 
European VCD service

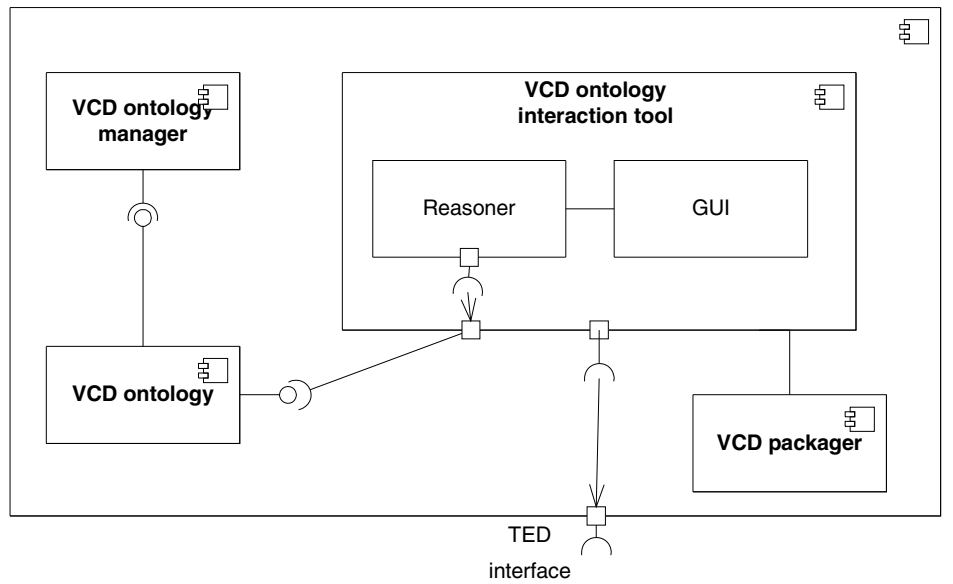

Fig. 5. Components of the European VCD service

The core functionality of the European VCD System is the VCD ontology interaction tool. It provides the graphical user interface and enables the generation of a list of evidences that are in accordance with the rule set mentioned in the previous section. The ontology is queried through two reasoner components, one which manages the rule set related to tenderer structures and one which manages the rule set in relation to the criteria-to-evidence mapping and the cascading rules. The procedure to map a list of criteria from one country to a set of evidences from another country can be described through the following five steps (the first step is optional and depends on the publication procedure that is chosen by the contracting authority):

1. Some contracting authority may refer to particular evidences in the contract notice/call for tender instead of using national criteria. In this case at first the correlating national criteria in the contracting authority's country have to be identified (optional).

2. In a second step the national qualification criteria are mapped to common European criteria serving as a pivotal element. The European criteria may be extended through virtual criteria that describe requirements which are unique to specific countries.

3. In a third step the mapping between the European criteria and the national criteria of the economic operator's country is performed.

4. The national criteria of the economic operator's country are used in the next step to identify the correlating evidences.

5. Finally the rule set (e.g. cascading rules) of the contracting authority is applied to the evidences identified in the country of the economic operator. This ensures that the evidences are correctly prepared under the conditions of the contracting authority.

The calculation of the mapping is performed by using the mapping tree defined within the ontology. 
When the ontology interaction tool has calculated the relevant evidences, the user, i.e., the economic operator, retrieves a VCD package skeleton (which is an XML document) which refers to an XML schema defined for the VCD document container. The XML document generated by the European VCD System is called a skeleton, as it does not yet include the individual evidences. The component which compiles this VCD package skeleton is called the VCD packager. The user retrieves this VCD package skeleton and, in a next step, contacts his/her national VCD service provider, who can collect all evidences from the issuing bodies and who can compile a full VCD package for the economic operator.

With the compilation and provision of a VCD package skeleton, the service of the European VCD System is completed. The European VCD System is planned to be publicly available and maintained centrally at European level.

\section{Concluding Remarks and Outlook}

One of the major objectives of the PEPPOL project is to facilitate EU-wide interoperability in public eProcurement. Therefore common principles and technical solutions have to be developed that are applied within all the Member States. eProcurement requires efforts to be made by public administrations, in particular to exploit new technologies for interoperability that enable easy information accessibility and improve the availability of pan-European services and interaction among citizens and businesses [8].

The VCD, as one of the key building blocks of the PEPPOL project, should support economic operators in any European country to draw on company information which is already registered somewhere in its home country and to submit these evidences electronically to any public sector awarding entity in Europe. The evidences and the underlying legislation currently differ from Member State to Member State: this makes it difficult for economic operators to participate easily in foreign public procurements procedures.

In this paper, we have presented a concept for a European VCD System. We described the concept according to the legal and technical specifications that provide an opportunity to harmonise the different national systems in Europe without changing them.

The next steps in the PEPPOL project are to start with the implementation of pilots. The project will thus undertake an incremental prototyping procedure with a proof of concept pilot, a test pilot, and a production pilot. It is planned that, in November 2010, the European VCD System will run in its first production version.

Even though the concept for the European VCD System provides an innovative, intelligent and advanced service to facilitate cross-border public eProcurement, there are a number of challenges that the project team will have to face to achieve the substantial objectives of the initiative. Some of these challenges are a) to define the overall governance process, b) to settle procedures for the maintenance of the ontology and rule set for criteria-to-evidence mappings and c) to find an appropriate host for the European VCD System, which will ensure that the ontology always stays up-to-date and legally compliant with European and national public procurement 
laws while the ownership of the ontology remains with the individual Member States.

The VCD and the European VCD System will lower the transaction costs of economic operators by supporting them in creating a qualified VCD package in their home country. With the VCD it will be easier for business entities to make crossborder submissions of evidences and, thereby, to increase the ratio of meeting the legal and formal company qualification criteria and selection criteria for the awarding phase of a tender.

Acknowledgements. PEPPOL is co-funded by the European Commission under the Competitive and Innovation Programme, Information and Communication Technologies Policy Support Programme (ICT PSP). This publication reflects the views only of the authors, and the Commission cannot be held responsible for any use which may be made of the information contained in it.

\section{References}

1. Charalabidis, Y. (ed.): Interoperability in Digital Public Services and Administration: Bridging E-Government and E-Business. IGI Global, Hershey (2010)

2. European Commission, Linking up Europe: The importance of Interoperability for eGovernment Services Commission Staff Working paper, Commission of the European Communities, Brussels (2003)

3. European Commission, Directive 2004/18/EC of the European Parliament and of the Council of 31 March 2004 on the coordination of procedures for the award of public works contracts, public supply contracts and public service contracts. Official Journal of the European Union, 30.04.2004 (2004)

4. European Commission. i2010 eGovernment Action Plan: Accelerating eGovernment in Europe for the Benefit of All. European Commission: Brussels, COM, 173 (2006)

5. European Commission, Action plan for the implementation of the legal framework for electronic public procurement. European Commission, Brussels (2004)

6. European Commission, Directive 2004/17/EC of the European Parliament and of the Council of 31 March 2004 coordinating the procurement procedures of entities operating in the water, energy, transport and postal services sectors. Official Journal of the European Union, 30.04.2004 (2004)

7. Guijarro, L.: Analysis of the Interoperability Frameworks in eGovernment Initiatives. In: Traunmüller, R. (ed.) EGOV 2004. LNCS, vol. 3183, pp. 36-39. Springer, Heidelberg (2004)

8. IDABC, EIF: European Interoperability Framework for Pan-European E-Government Services. European Communities (2004)

9. IDABC, EIF: Draft for public comments - as basis for the European Interoperability Framework for Pan-European E-Government Services 2.0. European Communities (2008), http: / / ec.europa.eu/idabc/servlets/Doc?id=31597 (accessed on October 15,2010$)$

10. Kubicek, H., Cimander, R.: Interoperability in eGovernment - A Survey on Information Needs of Different EU Stakeholders. European Review of Political Technologies 3, 59-74 (2005) 
11. Peristeras, V., Tarabanis, K.: The Connection, Communication, Consolidation, Collaboration Interoperability Framework (C4IF) For Information Systems Interoperability. IBIS International Journal of Interoperability in Business Information Systems 1(1), 61-72 (2006)

12. Scholl, H.J., Klischewski, R.: E-Government Integration and Interoperability: Framing the Research Agenda. International Journal of Public Administration 30(8), 889-920 (2007)

13. Staab, S., Studer, R. (eds.): Handbook on Ontologies. Springer, Berlin (2004)

14. Wimmer, M.A.: Integrated service modeling for online one-stop Government. EM - Electronic Markets, Special Issue on e-Government 12(3), 1-8 (2002) 